\title{
Examples of modern methods of measuring deformations
}

\author{
Tomasz Domański ${ }^{1, *}$ \\ ${ }^{1}$ Institute of Mechanics and Machine Design Foundations, Czestochowa University of Technology, \\ Dabrowskiego 73, 42-200 Częstochowa, Poland, EU
}

\begin{abstract}
The work presents examples of possibilities created by multi-unit 3D correlation system. Experience is the non-contact measurement of displacement and strains of slender compression bars or tensile samples. Experimental research show that as a result of axial compression of slender elements with the length substantially exceeding the cross-sectional dimensions, element destruction occurs at loads less than the respective compressive strength, resulting in deformation of the object. We present the results of numerical analysis, compared with exercise of carrying on a test bench.
\end{abstract}

Keywords: image correlation system, strains, deformations

\section{Introduction}

Today's facilities are characterized by high functional diversity, which, while maintaining high quality of workmanship, is very difficult. Products are increasingly demanding, and consequently products have increasingly complex 3D geometry. Measurement tools should combine the speed of collection of measurement points with high accuracy. The use of a non-invasive measurement method makes it possible to detect defects much faster without the need for specialist preparation of test specimens. The advantage of using optical measurement methods of deformation, strains or stress distribution is the ability to identify changes in the surface of the examined material at the microscale level, allowing for early identification of the process before its dynamic development. The digital image correlation method uses images taken at the same time by several optical cameras with high sensitivity to deformation and vibration of the object being observed. This method of measurement is increasingly used to determine the components of stresses, deformations or displacements in laboratory conditions, and to identify defects in machine components under the influence of static loads or dynamic variables over time [1]. Measurement methods allow for easier adaptation to the measurement of parts of machine parts in their natural industrial environment under real operating conditions.

\footnotetext{
* Corresponding author: domanski@imipkm.pcz.pl

Reviewers: Vladimir Dekýš, Grzegorz Domek
} 


\section{Image correlation system 3D}

The Q-400 system used with the ISTRA 4D software is a multifunctional non-contact tool for measuring the deformation of a tested object in both two- and three-dimensional coordinate systems Fig. 1.

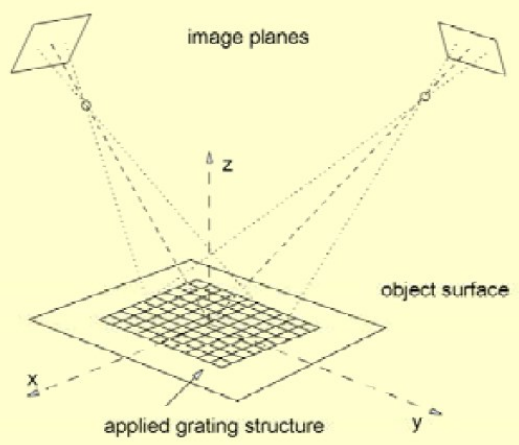

Fig. 1. Schematic diagram [2]

Dimensions and positions of the two points in the state before and after the deformation are considered. The measurement method consists in correlating digital images recorded with two or more cameras. The surface of the object is covered with a layer of white and black paint. Measurement is done by tracking the surface covered by the affected surface, subjected to a load.

\section{Examples of research into mechanical phenomena}

Two tests were performed to verify system performance. The first was the determination of the deformation in tensile test specimens made of the base material and with a welded joint, while the other consisted in determining the displacement of the compression slim bar.

\subsection{Tensile test of samples with welded joint}

The tensile test is one of the basic tests for determining the mechanical properties of materials.Universal strength machine Zwick\&Roel Z100 is used with extensometer Multisens in all performed tension tests [3]. The accuracy of the strength machine is up to $1 \mathrm{~N}$ in force and $1 \mu \mathrm{m}$ in displacement Fig. 2. Samples for the tension test were made from welded joints according to norm PN-EN ISO 6892-1.

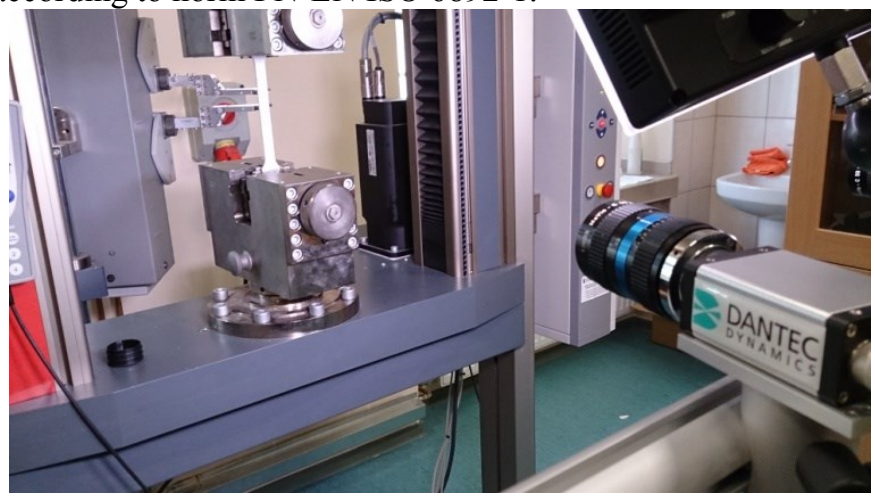

Fig. 2. Tension test: universal strength machine Zwick\&Roel Z100, with the Dantec system 
Butt welding is performed for sheets made of S355 steel. Welding process proceed without a gap in the shielding gas $82 \% \mathrm{Ar}+18 \% \mathrm{CO}_{2}$, the gas flow is $18 \mathrm{1} / \mathrm{min}$, wire speed $6 \mathrm{~m} / \mathrm{min}$ and welding speed set to $\mathrm{v}=1 \mathrm{~m} / \mathrm{min}$. The distance between heat sources $\mathrm{d}=2 \mathrm{~mm}$. Laser beam is the leading heat source in the tandem.

Optical cameras used to record strains in the tension test are equipped with $50 \mathrm{~mm}$ lenses and have maximum resolution $2048 \times 2048$ pixels each. This allowed determining the full size of analyzed sample in the working area of universal testing machine. System of three cameras is used in the experiment. Cameras are mounted on the beam which is supported by two fully adjustable tripods. Strain fields are measured for the entire tension cycle. Trigger mechanism is created in Istra4D software for the measurement. Pictures are made for every time increment $\Delta \mathrm{t}=0.4 \mathrm{~s}$.

Three tension tests were performed for the base material as well as hybrid welded samples. Results of performed tests are presented in $\mathrm{F} \rightarrow \Delta \mathrm{L}$ diagrams (Fig. 3). There has been a slight decrease in yield strength and tensile strength in tensed welded joints simultaneously with a decrease of elongation. This can be caused by non heterogeneity of structure in the area of heat influence on the material.

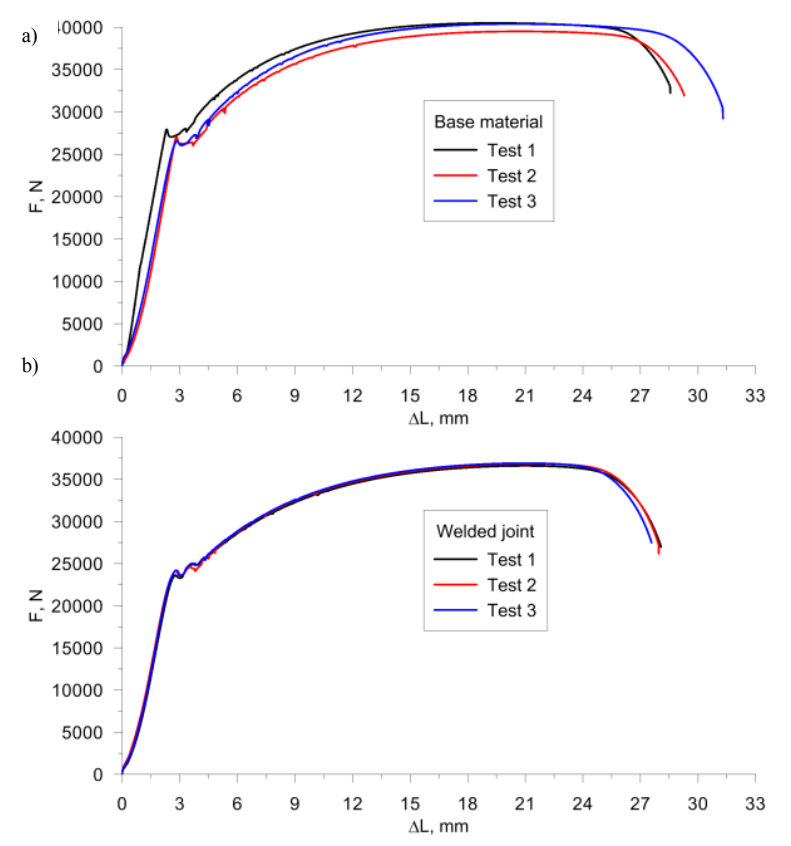

Fig. 3. $\mathrm{F} \rightarrow \Delta L$ diagrams: a) tensed base material, b) tensed welded joint

Figure 4 presents comparison of strain fields in tensed base material and welded joint at the various times the formation of the neck. It can be observed that the weld and HAZ has a significantly lower strain compared to the base material, which is directly related to the nature of the microstructure in these areas (see. Fig. 4).

Distribution of strain $\varepsilon_{\mathrm{y}}$ along the length of tensed sample $(55 \mathrm{~mm}$ in both direction from the central point of the sample) is illustrated in Fig. 5. Strain distribution is shown in the central axis $y$ for the base material and welded joint at different times. Visible decrease of strain is present in the joint where HAZ is present [4,5]. The slight increase of strain in the weld can be because of the inaccurate selection of an additional material in GMAW method. It can be observed that for the base material higher values of strain $\varepsilon_{\mathrm{y}}$ are present in comparison to welded joint. 


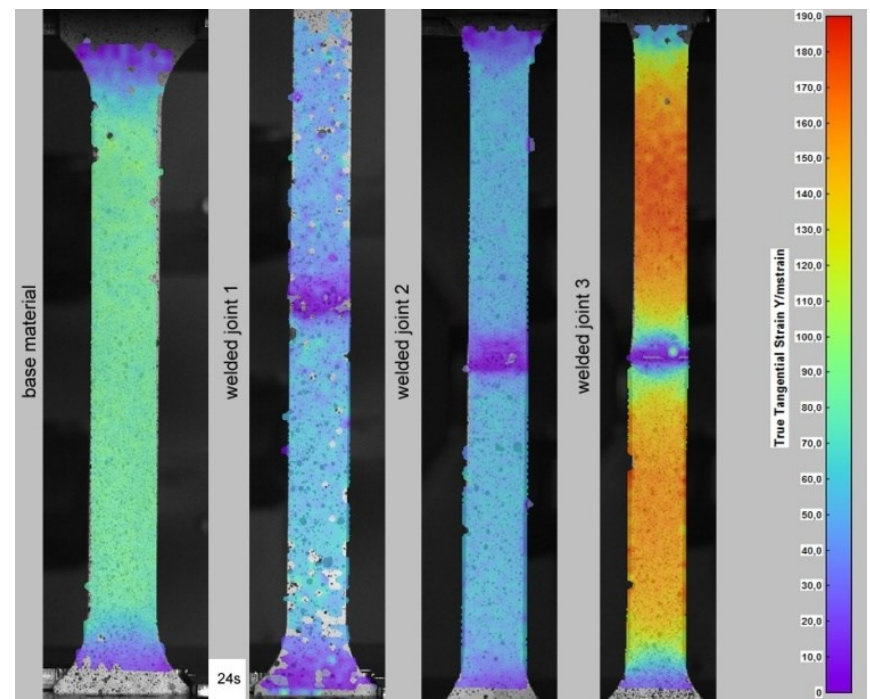

Fig. 4. Comparison of longitudinal strains for time t-24 s

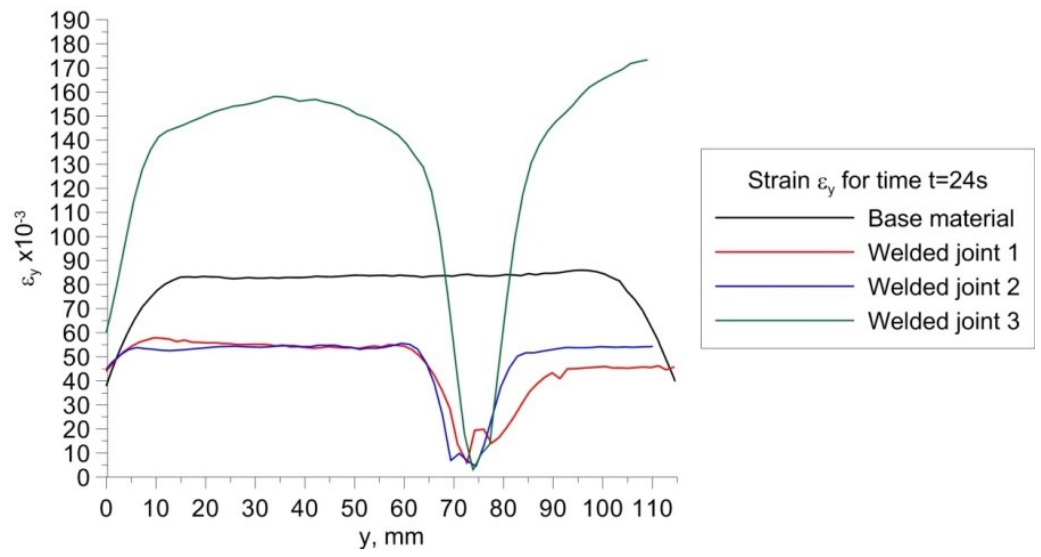

Fig. 5. Distribution of strain $\varepsilon_{\mathrm{y}}$ in the central axis $y$

\subsection{Compression test of slender bar}

In the conducted experiment, two cases were considered. The tests performed differed in the way the bar was loaded, as shown in the figure below (Fig 6.). 

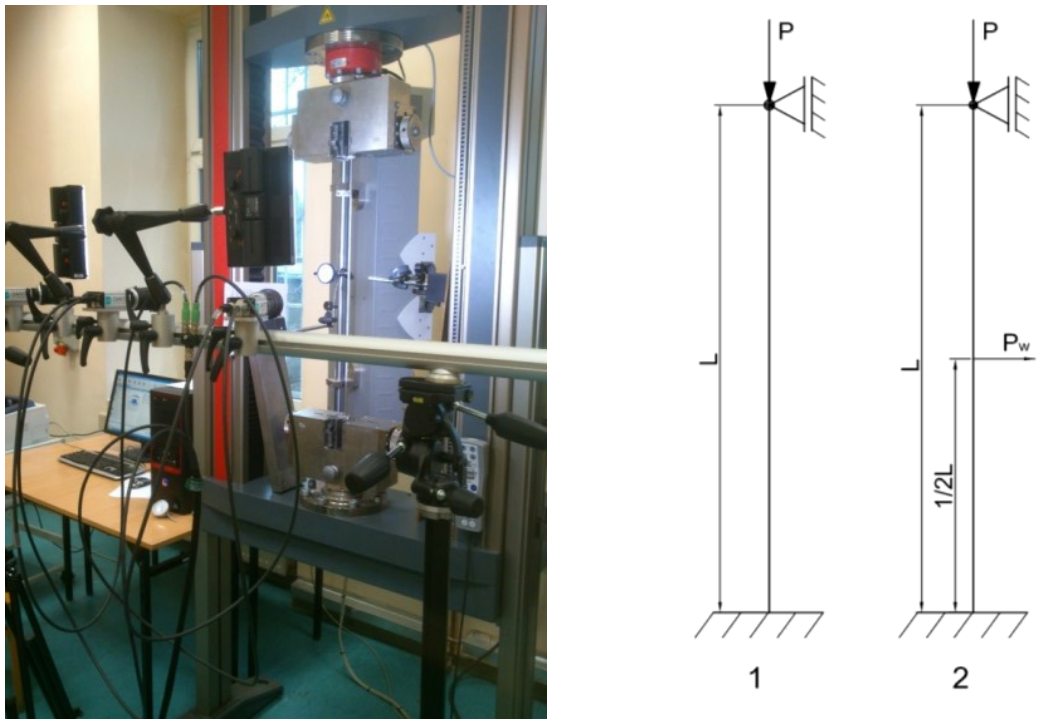

Fig. 6. View of the test stand, bar fixings for the cases considered

Test object in the form of a bar of total length $L=708.9[\mathrm{~mm}]$ and circular cross-section with diameter $D=6[\mathrm{~mm}]$, made of stainless steel AISI 304 , it is fixed at the base and joint at the place of axial force $\mathrm{P}$ (case no.1 and no.2). In addition, for case no. 2, the tested element was additionally loaded by a horizontal force that forces the buckling direction $P_{w}$, applied at half the total length of the element. Strain of the element due to loss of stability was recorded independently by three cameras in the working area, defined as the distance $170[\mathrm{~mm}]$ from bar anchorage [6,7].
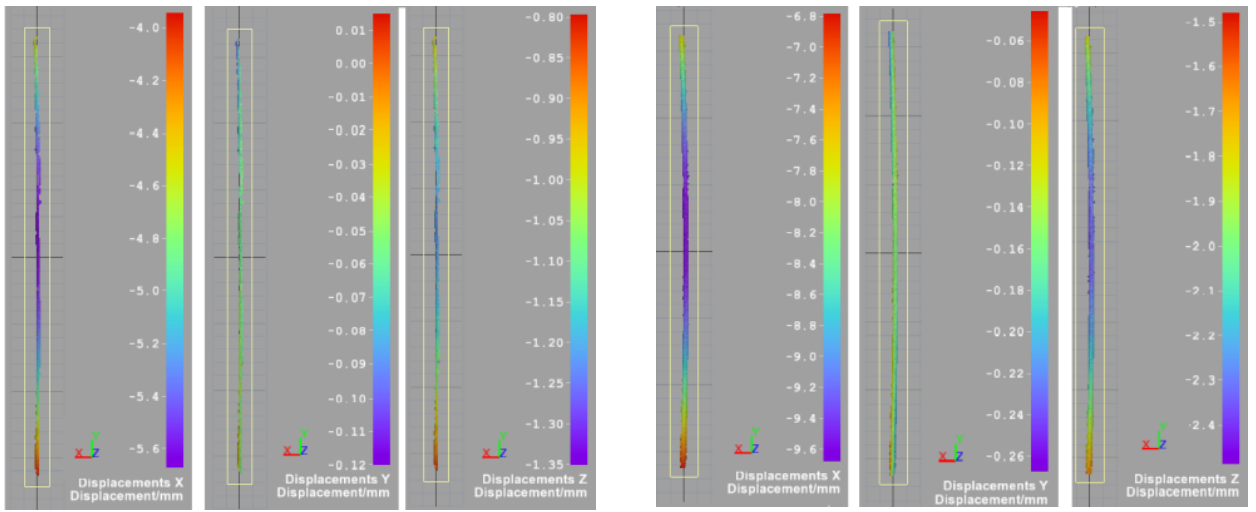

Fig. 7. Results for option 1 and 2

\section{Conclusions}

The use of multi-camera 3D correlation system allowed the analysis of deformation for the selected material points throughout the measuring sample. Use of the system allowed the analysis of deformation and strain distributions in the weld and heat affected zone during tension test. It can be observed that lower strains occur in heat affected zone in comparison to the base material which in reference to pictures of microstructure confirm partial hardening of this zone. Visible increase of strain $\varepsilon_{\mathrm{y}}$ in the weld may be due to the inaccurate 
selection of an additional material in GMAW method. Obtained results allow for a thorough analysis of mechanical properties separate zones of the joint (weld, HAZ) and do not limit the tensile test to determine the global strength and plastic properties of welded material.

In the second example, the use of the Dantec Dynamics measuring system has allowed analysis of displacements and deformations in all directions while attempting to ax the rod. The action of the additional $P_{w}$ force applied horizontally at half the length of the rod results in larger deformations of the element in the direction of the force. Obtained experimental results may be very helpful in verifying mathematical and numerical models of thermomechanical phenomena occurring in welding processes.

\section{References}

1. K. Patorski, Interferometria laserowa. Oficyna Wydawnicza Politechniki Warszawskiej, 214-261 (2005)

2. C. Herbst, K. Splitthof, Basic of 3D Digital Image Correlation. (Ulm, Dantec Dynamics $\mathrm{GmbH}$ )

3. T. C. Chu, W. F. Ranson, M. A Sutton, W. H. Peters, Application of digital-imagecorrelation techniques to experimental mechanics. Experimental Mechanics 25 (3), 232-244 (1985)

4. T. Skrzypczak, A finite element multi-mesh approach for heat transport between disconnected regions. Procedia Engineering 177, 204-209 (2017)

5. M. Kubiak, W. Piekarska, Comprehensive model of thermal phenomena and phase transformations in laser welding process. Computers \& Structures 172, 29-39 (2016)

6. M. R. Gower, R. M. Shaw, Towards a planar cruciform specimen for biaxial characterization of polymer matrix composites. Applied Mechanics and Materials 2425, 115-120 (2010)

7. L. Sowa, Z. Saternus, M. Kubiak, Numerical modelling of mechanical phenomena in the gantry crane beam. Procedia Engineering 177, 225-232 (2017) 